\title{
Assessing heat load in drylot dairy cattle: Refining on-farm sampling methodology
}

\author{
Grazyne Tresoldi, ${ }^{*}$ Karin E. Schütz, $†$ and Cassandra B. Tucker*1 \\ *Department of Animal Science, University of California, Davis 95616 \\ †AgResearch Ltd., Hamilton 3240, New Zealand
}

\begin{abstract}
Identifying dairy cattle experiencing heat stress and adopting appropriate mitigation strategies can improve welfare and profitability. However, little is known about how cattle use heat abatement resources (shade, sprayed water) on drylot dairies. It is also unclear how often we need to observe animals to measure high heat load, or the relevance of specific aspects of this response, particularly in terms of panting. Our objectives were to describe and determine sampling intervals to measure cattle use of heat abatement resources, respiration rate (RR) and panting characteristics (drooling, open mouth, protruding tongue), and to evaluate the relationship between the latter 2. High-producing cows were chosen from 4 drylots ( 8 cows/dairy, $\mathrm{n}=32$ ) and observed for at least $5.9 \mathrm{~h}$ (1000 to $1800 \mathrm{~h}$, excluding milking) when air temperature, humidity, and the combined index averaged $33^{\circ} \mathrm{C}, 30 \%$, and 79 , respectively. Use of heat abatement resources was recorded continuously; RR and the presence and absence of each panting characteristic were recorded every 5 min. From the observed values, estimates using the specified subsampling intervals were calculated for heat abatement resource use $(1,5,10,15,20,30,60,90$, and $120 \mathrm{~min})$, and for RR and panting (10, 15, 20,30,60, 90, and $120 \mathrm{~min})$. Estimates and observed values were compared using linear regression. Sampling intervals were considered accurate if they met 3 criteria: $R^{2} \geq 0.9$, intercept $=0$, and slope $=1$. The relationship between $\mathrm{RR}$ and each panting characteristic was analyzed using mixed models. Cows used shade (at corral or over feed bunk) and feed bunk area (where water was sprayed) for about 90 and $50 \%$ of the observed time, respectively, and used areas with no cooling for 2 min at a time, on average. Cows exhibited drooling $(34 \pm 4 \%$ of observations) more often than open mouth and protruding tongue $(11 \pm 3$ and $8 \pm 3 \%$ of observations, respectively). Respiration rate varied depending on the presence of panting (with vs. without drool present: 97
\end{abstract}

Received April 22, 2016

Accepted June 22, 2016

${ }^{1}$ Corresponding author: cbtucker@ucdavis.edu \pm 3 vs. $74 \pm 3$ breaths/min; open vs. closed mouth: $104 \pm 4$ vs. $85 \pm 4$ breaths/min; protruding vs. nonprotruding tongue: $105 \pm 5$ vs. $91 \pm 5$ breaths/min). Accurate estimates were obtained when using sampling intervals $\leq 90 \mathrm{~min}$ for $\mathrm{RR}, \leq 60 \mathrm{~min}$ for corral shade and sprayed water use, and $\leq 30$ min for drooling. In a hot and dry climate, cows kept in drylots had higher RR when showing panting characteristics than when these were absent, and used shade extensively, avoiding areas with no cooling. In general, 30 min intervals were most efficient for measuring heat load responses.

Key words: heat stress, behavior, cooling, sprinkler

\section{INTRODUCTION}

In the arid western United States, about 1.8 million cows are kept in drylots (open, dirt-based pens), comprising $30 \%$ of dairy farms (USDA, 2010). Compared with other housing types, this system has several benefits, including lower capital costs (Stokes and Gamroth, 1999), lower disease prevalence (e.g., lameness and mastitis), and better reproductive outcomes (USDA, 2010). However, because drylots are found mainly in hot, dry regions such as California, exposure to heat load during the summer creates economic and ethical concerns relating to reduced milk production, infertility, and mortality (St-Pierre et al., 2003; von Keyserlingk et al., 2013). Identifying dairy cattle experiencing high heat load and adopting appropriate mitigation strategies can lead to improvements in animal welfare and profitability.

To help their cattle cope with heat load, dairy producers commonly provide heat abatement resources such as drinking water, shade, fans, or sprayed water (USDA, 2010). However, little is known about how cattle use such resources on commercial drylot operations. To assess the effectiveness of heat abatement resources, the behavioral and physiological strategies cattle use to reduce heat gain or to promote heat loss can be measured. Relatively short-term responses to hot weather include increased use of shade (Schütz et al., 2008, 2009, 2010), sprayed water (Legrand et al., 2011; Chen et al., 2013), and higher respiration rate, along with panting (Brown-Brandl et al., 2005; Gaughan et al., 
2008). These responses provide a well-established set of variables to assess heat load, but aspects of their measurement require refinement.

Determining appropriate measurement strategies is essential for generating accurate estimates when assessing heat load. Although continuous observation quantifies a response accurately (Martin and Bateson, 2007), many practical issues are associated with this sampling method. It can be time-consuming, labor-intensive, and highly reliant on technology (e.g., video cameras, data loggers), which is not always available for on-farm assessments. Alternatively, some measures can be sampled at fixed intervals over time without compromising the results obtained (Mitlöhner et al., 2001; Ledgerwood et al., 2010), but it remains unclear how often we need to observe cattle to capture responses to heat load. Measurement of respiration rate, for example, varies in the literature from every 15 min over a 24 -h period (Brown-Brandl et al., 2005) to once a week (Keister et al., 2002). Variation across studies suggests an opportunity to identify appropriate sampling methods for such measures to improve the reliability and accuracy of the results.

Another methodological concern related to measures of heat load is the way they are described and recorded. Panting, for example, has been thought to be a more accessible tool (i.e., easier to measure than respiration rate, for example) for identifying cows that experience high heat load. This response has been recorded using a scoring system (Mader et al., 2006; Gaughan et al., 2008), with characteristics to define panting intensity including drooling, whether the mouth is open or closed, whether the tongue is protruding or not, breathing rhythm, and posture. However, the biological meaning of these different characteristics and their relationship with respiration rate are not clearly understood. In addition, the subjectivity of description of some of these characteristics can contribute to poor reliability, and, possibly, low accuracy. Thus, our objectives were (1) to describe the use of heat abatement resources on commercial drylot operations, and (2) to refine the methodology used to assess heat load in dairy cows by determining accurate sampling intervals to measure respiration rate, panting, and use of heat abatement resources, and by evaluating the relationship between respiration rate and specific panting characteristics such as drooling, open mouth, and protruding tongue.

\section{MATERIALS AND METHODS}

\section{Farms and Animals}

All procedures involving animals were approved by the University of California, Davis, Institutional Ani- mal Care and Use Committee. This study was carried out from July to August 2014 in 4 drylot dairies in the Central Valley of California (Tulare and Kings Counties). The 4 operations varied in terms of heat abatement strategies provided, milk production, and herd size (Table 1). On each farm, 8 Holstein-Friesian cows were randomly selected from the high-producing group of cows (total $n=32$ ). The selected cows were identified with numbered collars and tail spray paint. Individual and whole-group data for DIM, lactation number, and milk yield were obtained from computer records (Dairy Comp 305, Valley Agricultural Software, Tulare, CA) and are summarized in Table 1.

\section{Data Collection}

Data were recorded from 1000 to $1800 \mathrm{~h}$, excluding when cows were away from the home pen for milking, averaging $6.6 \mathrm{~h}$ of observation/cow (range $=5.9$ to 7.7 h). This window was chosen to capture the warmest daily weather in this region. Each day, 2 cows were tracked individually by 2 observers from outside the pen (1 observer/cow). Observations lasted $4 \mathrm{~d}$ /dairy, for a total of 8 cows/operation, 32 in total. Binoculars (Powerview 7-15 $\times 25$, Bushnell, Overland Park, KS) were used when necessary. Two observers recorded all the measurements taken.

Use of Heat Abatement Resources. The use of heat abatement resources was recorded continuously based on the location of each cow in the pen. The home pen was divided into 4 different locations: feed bunk (concrete-floored surface behind the area where feed was provided), water trough (2 cow body-lengths area around the water source), corral shelter (dirt-floored surface underneath the roof of the shelter or within the shadow it projected, when visible), and open area (any other dirt-floored area that did not correspond to any location described above). At the start of observation, a cow was recorded as using a location where she had the majority of her hooves (if hooves were evenly split across areas, then we recorded the location where she had her front hooves). When the cow changed her location, the starting time was recorded as the second when she placed the first (front) hoof in the next location. The use of heat abatement was defined based on the resources provided on each farm: shade overall (corral shelter or shaded feed bunk), corral shade (corral shelter), shade + sprayed water (shaded feed bunk), sprayed water (unshaded feed bunk), and water trough. Except for dairy 3, where shade was not provided at the feed bunk (thus, unshaded feed bunk), all other forms of heat abatement resources were found in all farms. None of the farms provided fans. For each loca- 
Table 1. Heat abatement strategies provided on 4 commercial drylot dairy farms, including size of high-producing group and production data for both the high-producing group and the subset of 8 observed cows in each farm

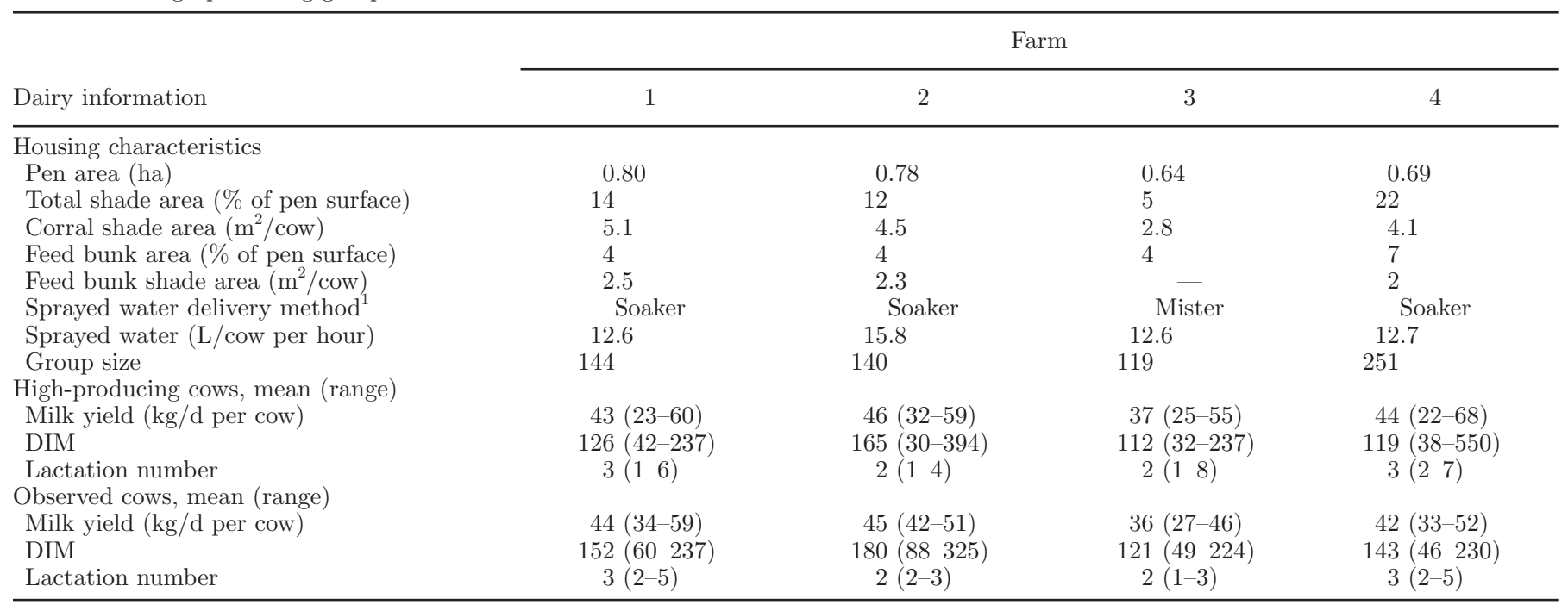

${ }^{1}$ Soakers sprayed water intermittently during the entire observation period; misters sprayed water continuously after $1400 \mathrm{~h}$.

tion, interobserver reliability was calculated using the kappa coefficient $(\kappa \geq 0.93)$.

Physiological Measures. Respiration rate and panting characteristics were recorded every $5 \mathrm{~min}$, within the first minute of the interval. Respiration rate was measured as time for 10 flank movements and converted to breaths per minute to facilitate comparisons with other studies. Immediately after respiration rate was taken, cows were observed for $10 \mathrm{~s}$ to identify the presence and absence of panting characteristics (unless they were feeding, drinking, or licking), using 1-0 sampling (Martin and Bateson, 2007). At the time, 5 characteristics were recorded: drooling (saliva coming out of the cow's mouth when she was not ruminating), open mouth (space between the lips was visible when cow was not ruminating), closed mouth (space between the lips was not visible), protruding tongue (at least the tip of the tongue crossed the edge of the bottom lip) and tongue inside the mouth (tongue rested in the floor of the mouth). Except for drooling, we also determined whether panting was continuous or intermittent during the 10-s interval. Panting was considered intermittent when a cow showed both the presence (e.g., open mouth), and the absence (e.g., closed mouth) of that panting characteristic; panting was considered continuous when a cow showed only the presence of a determined sign of panting. Interobserver reliability was calculated using regression analysis for respiration rate $\left(\mathrm{R}^{2}=0.97\right.$; intercept $=0.0, P=0.96$; slope $=0.99$, $P=0.71)$, and the kappa coefficient for each panting characteristic $(\kappa \geq 0.94)$.

Environmental Conditions. A portable weather station (WS-16; Novalynx Corp., Auburn, CA) was placed near the high-producing pen in all dairies. We recorded information on air temperature and black globe temperature ( $\mathbf{T}$ and $\mathbf{B G T},{ }^{\circ} \mathrm{C}$ ), wind speed (WS, m/s), relative humidity $(\mathbf{R H}, \%)$, solar radiation $\left(\mathrm{W} / \mathrm{m}^{2}\right)$, and precipitation $(\mathrm{mm})$ every $5 \mathrm{~min}$. We calculated additional measures of heat load, such as temperature-humidity index (THI) and heat load index (HLI) using the following equations as from Kelly and Bond (1971), and Gaughan et al. (2008), respectively:

$$
\begin{gathered}
\mathrm{THI}=(1.8 \times \mathrm{T}+32)-[(0.55-0.0055 \times \mathrm{RH}) \\
\times(1.8 \times \mathrm{T}-26)], \\
\mathrm{HLI}=\text { if }[\mathrm{BGT}>25,8.62+(0.38 \times \mathrm{RH})
\end{gathered}
$$

\section{Data Management and Statistical Analysis}

All statistical procedures were done using SAS software (SAS Institute, 2009). We used descriptive analyses to characterize respiration rate, panting characteristics, and the total time, bout duration (including only bouts with a known beginning and ending time, excluding those interrupted by farm staff), and number of events where cows used each heat abatement resource. We also used a correlation analysis (PROC CORR) to evaluate the relationship between corral shade and feed bunk use in all farms (shade + sprayed water on 3 farms, and sprayed water only on 1 farm). 
Table 2. Summary (averages of mean, minimum, and maximum) of weather conditions during $24 \mathrm{~h}$ and the observation period ${ }^{1}$

\begin{tabular}{|c|c|c|c|c|c|c|}
\hline Weather variable & \multicolumn{3}{|c|}{ Observation period } & \multicolumn{3}{|c|}{$24 \mathrm{~h}$} \\
\hline Air temperature $\left({ }^{\circ} \mathrm{C}\right)$ & $33.2(2.7)$ & 27.7 & 38.2 & $27.9(5.4)$ & 19.7 & 36.4 \\
\hline Heat load index & $90(5)$ & 78 & 102 & $76(14)$ & 55 & 98 \\
\hline Black globe temperature $\left({ }^{\circ} \mathrm{C}\right)$ & $44.2(4.0)$ & 33.8 & 52.4 & $32.9(10.0)$ & 19.3 & 49.4 \\
\hline Solar radiation $\left(\mathrm{W} / \mathrm{m}^{2}\right)$ & $613(192)$ & 101 & 845 & $256(308)$ & 0 & 909 \\
\hline
\end{tabular}

${ }^{1}$ Observation periods were from 1000 to $1800 \mathrm{~h}$ daily.

Sampling Intervals. For use of shade overall $(\mathrm{n}=$ $32)$, corral shade $(\mathrm{n}=32)$, shade + sprayed water $(\mathrm{n}$ $=24)$, and water trough $(\mathrm{n}=32)$, we extracted estimates for 9 sampling intervals $(1,5,10,15,20,30,60$, 90, and $120 \mathrm{~min}$ ) from continuous data using the EXPAND procedure, selecting round minutes (hh:mm:00). Due to the small sample size $(\mathrm{n}=8)$, we excluded the sprayed water only variable from data analysis. For each sampling interval, we calculated the total time each cow spent using each heat abatement resource by multiplying the total number of observations in each location by the sampling interval length. For respiration rate and the proportion of time cows exhibited each panting characteristic $(\mathrm{n}=32)$, we used the values obtained every $5 \mathrm{~min}$ to estimate data collected using 7 sampling intervals $(10,15,20,30,60,90$, and $120 \mathrm{~min}$ ). To compare the sampling estimates against the continuous or 5-min measurements, we used linear regression (PROC REG) to generate 3 parameters: the coefficient of determination $\left(\mathrm{R}^{2}\right)$ and whether the slope and intercept differed from 1 and 0 , respectively. We adjusted $P$-values using a Bonferroni correction (PROC MULTTEST) to minimize family-wise error, reducing the likelihood of false-positive interactions.

Relationship Between Respiration Rate and Panting Characteristics. Initially, we used paired $t$-tests to compare the effects of $10 \mathrm{~s}$ intermittent versus continuous panting (both for open mouth and protruding tongue) on respiration rate. Next, we evaluated the relationship between respiration rate and the presence and absence of each panting characteristic (i.e., drooling versus no drooling, open mouth versus closed mouth, protruding tongue versus tongue inside the mouth) using mixed models (PROC MIXED), including only cows that were observed panting (drooling, $\mathrm{n}=32$; open mouth, $\mathrm{n}=21$; protruding tongue, $\mathrm{n}$ $=15)$ to minimize modeling assumptions. Each model used variance components as the covariance structure, with fixed effect for panting characteristic and random effects for presence of panting characteristic nested within cow. We estimated degrees of freedom using the containment method.

\section{RESULTS}

\section{Weather}

Weather conditions for $24 \mathrm{~h}$ and observation periods are summarized in Table 2. Rainfall was $0 \mathrm{~mm}$ throughout the study.

\section{Responses to Heat Load}

Use of Heat Abatement Resources. Individual cow data for use of heat abatement resources are summarized in Figure 1. All following ranges presented are for average values. On average, cows spent $5.9 \pm 0.2$ $\mathrm{h}$ /observation period (range $=3$ to $7.7 \mathrm{~h}$ ) under shade overall, across $7 \pm 1$ bouts (range $=1$ to 22 ) of $54 \pm 5$ min each (range $=19$ to $123 \mathrm{~min}$ ). We observed similar bout lengths when cows were using the corral shade (54 $\pm 6 \mathrm{~min}$ (bout; range $=21$ to $125 \mathrm{~min})$, but cows visited this area less often ( $3 \pm 0$ visits; range $=1$ to 8$)$, resulting in less total use $(3.2 \pm 0.2 \mathrm{~h} /$ observation period; range $=0.02$ to $5.5 \mathrm{~h}$ ). On the 3 dairies with shade + sprayed water feed bunks, cows spent on average $3.6 \pm$ $0.1 \mathrm{~h} /$ observation period using this area (range $=0.8$ to $6.3 \mathrm{~h}$ ), across $5 \pm 1$ visits (range $=1$ to 19 ) of $49 \pm$ $8 \mathrm{~min}$ each (range $=16$ to $155 \mathrm{~min}$ ). Although cows in the dairy with the unshaded feed bunk (sprayed water only) spent similar amounts of time during each visit $(42 \pm 15 \mathrm{~min} /$ bout; range $=6$ to $125 \mathrm{~min})$, their visits were less frequent (mean $=2 \pm 0$ visits; range $=1$ to $4)$, resulting in less total use $(1.9 \pm 0.4 \mathrm{~h} /$ observation period; range $=0.4$ to $3.8 \mathrm{~h}$ ). The use of the corral shade and feed bunk areas (regardless of cooling strategies provided) were negatively correlated $(\mathrm{r}=-0.94, P$ $\leq 0.01$, Figure 2). On average, cows spent $12 \pm 3 \mathrm{~min} /$ observation period around the water trough (range $=1$ to $64 \mathrm{~min}$ ), across $5 \pm 1$ bouts (range $=1$ to 15 ) of 2.5 
$\pm 0.3 \mathrm{~min}$ each $($ range $=1$ to $8 \mathrm{~min}$ ). For areas where cooling was not provided, cows spent about $10 \pm 4$ min/observation period in total (range $=1$ to $107 \mathrm{~min}$ ), across $5 \pm 1$ bouts (range $=1$ to 15 ) of $2 \pm 1$ min each (range $=1$ to $27 \mathrm{~min}$ ).

Respiration Rate and Panting. Respiration rate averaged $80 \pm 4$ breaths/min. For individual cows, the lowest and the highest rates averaged $42 \pm 3$ and 123 \pm 4 breaths $/ \mathrm{min}$, respectively. Cows exhibited drooling (34 $\pm 4 \%$ of observations) more frequently than open mouth (11 $\pm 3 \%$ of observations) and protruding tongue ( $8 \pm 3 \%$ of observations). Of the open mouth and protruding tongue events, $80 \%$ were accompanied by drooling. Respiration rate was not different when

\section{a. Shade overall}

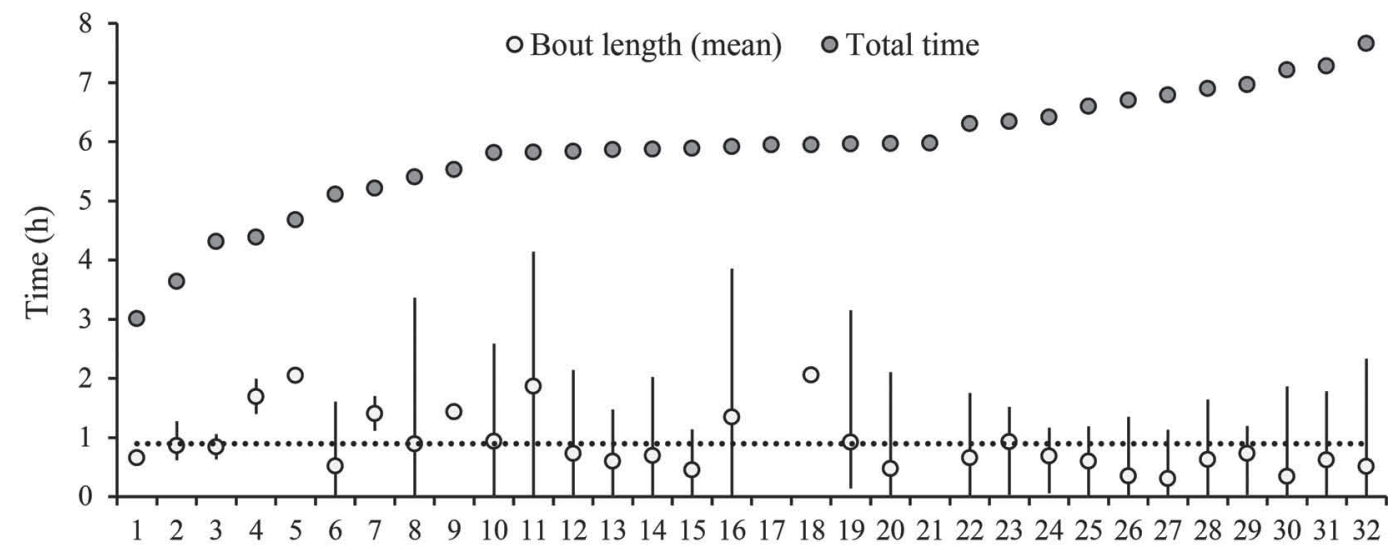

\section{b. Corral shade}

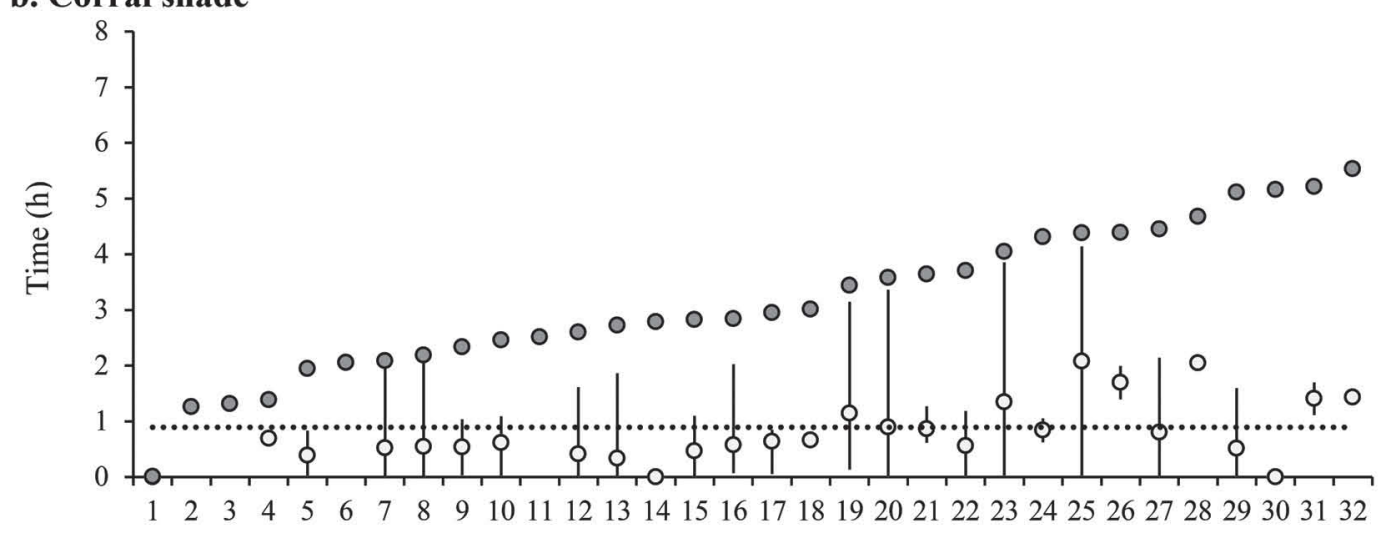

\section{c. Shade + sprayed water}

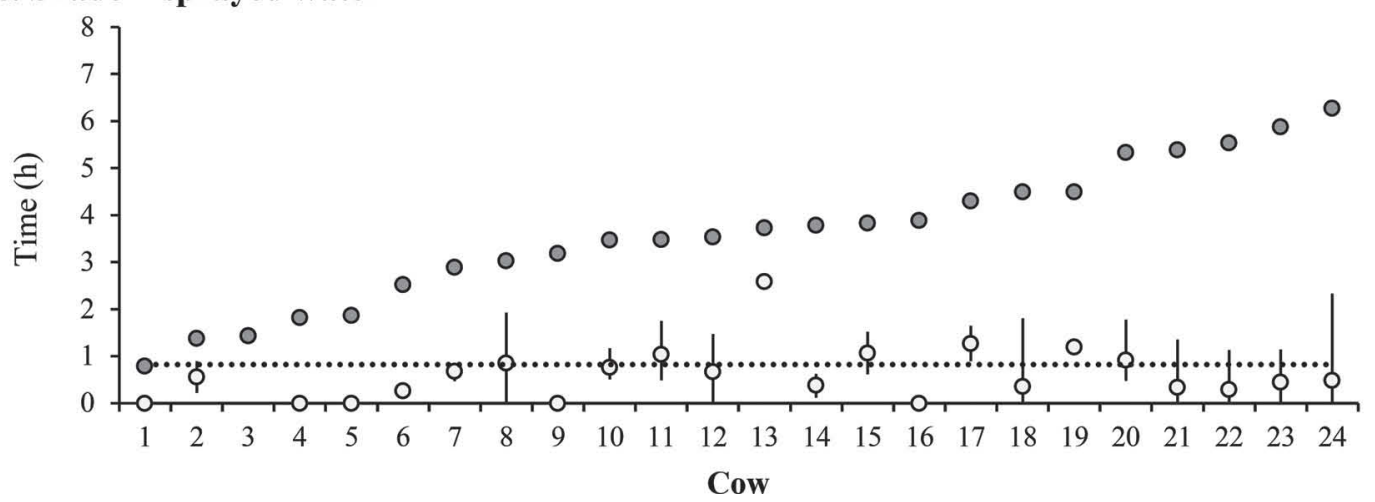

Figure 1. Mean bout length (h/bout) and total time (h/5.9 to $7.7 \mathrm{~h}$ of observation) each cow used (a) shade overall (n $=32)$, (b) corral shade $(\mathrm{n}=32)$, and $(\mathrm{c})$ sprayed water in dairies that had shaded feed bunks $(\mathrm{n}=24)$. The error bars represent the range for bout length $($ minimum and maximum), and the dotted line represents the overall average bout length. Cows are ordered by total time they spent using each location. 
- Shade + sprayed water O Sprayed water only

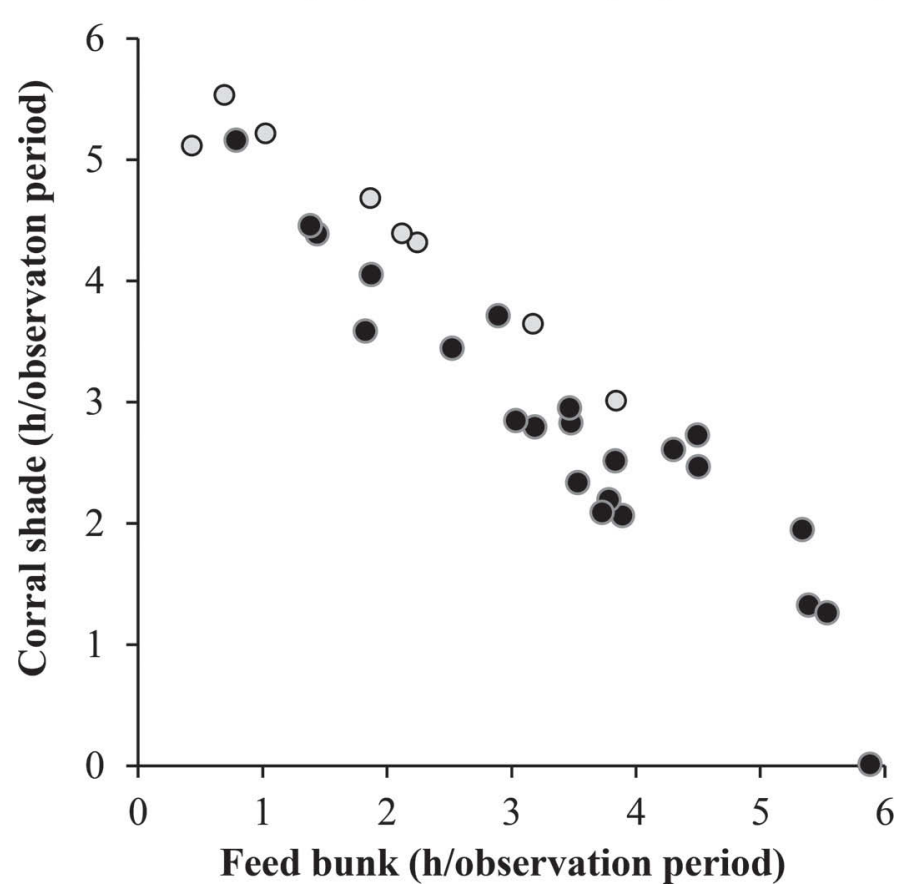

Figure 2. Relationship between feed bunk use in dairy farms that provided shade + sprayed water $(\mathrm{n}=3$ farms, 24 cows $)$ or sprayed water only ( $\mathrm{n}=1$ farm, 8 cows) and corral shade use (total time, $\mathrm{h}$ ). Each point represents 1 cow on $1 \mathrm{~d}$.

comparing $10 \mathrm{~s}$ intermittent and continuous open mouth $\left(102 \pm 1\right.$ vs. $113 \pm 2$ breaths $/ \mathrm{min} ; \mathrm{T}_{1,9}=1.4$, $P=0.20)$ or protruding tongue $(104 \pm 1$ vs. $115 \pm 2$ breaths $\left./ \mathrm{min} ; \mathrm{T}_{1,8}=1.6, P=0.15\right)$ panting. Respiration rate was higher when panting characteristics were present compared to when they were absent (drooling $\mathrm{F}_{1,31}$ $=185.2$, open mouth $\mathrm{F}_{1,20}=24.1$, protruded tongue: $\mathrm{F}_{1,14}=25.4, P \leq 0.01 ;$ Figure 3$)$.

\section{Sampling Intervals}

Coefficients of determination $\left(\mathrm{R}^{2}\right)$ decreased as sampling interval increased for all measurements taken (Table 3). Sampling intervals met all 3 criteria when $\leq 90 \mathrm{~min}$ for respiration rate, $\leq 60 \mathrm{~min}$ for use of the corral shade and shade + sprayed water, $\leq 30 \mathrm{~min}$ for shade use overall and presence of drooling, and $\leq 5 \mathrm{~min}$ for water trough use. Above these intervals, either the slope or intercept were statistically different than 1 or 0 , respectively, or $\mathrm{R}^{2}$ was smaller than 0.9 (Table 3 ). For open mouth and protruding tongue, $\mathrm{R}^{2} \geq 0.9$ was achieved using sampling intervals $\leq 20 \mathrm{~min}$. However, for these physiological measures, only the 15-min sampling estimates had slopes that were not different from 1 (Figure 4). These results suggest that there was no clear pattern of a rigorous sampling interval for open mouth and protruding tongue.

\section{DISCUSSION}

This was the first study to describe cattle use of heat abatement resources on commercial drylot operations, as well as the first to test the accuracy of sampling intervals to measure responses to heat load in cattle. During the observation period, cows spent almost the entire time using any type of shade available in their pens (corral or feed bunk, when available), and the use of open areas with no cooling lasted, on average, 2 min at a time. Regardless of the heat abatement resources provided in the feed bunk area (shade + sprayed water or sprayed water only), cows used this area during half of the time they were observed. Intervals of $30 \mathrm{~min}$ were most efficient for measuring heat load responses, except for open mouth and protruding tongue (where determination of sampling intervals was inconclusive) and time around water trough (which represented a small amount of the cows' time budget during the observed period). When showing drooling, open mouth, or pro-

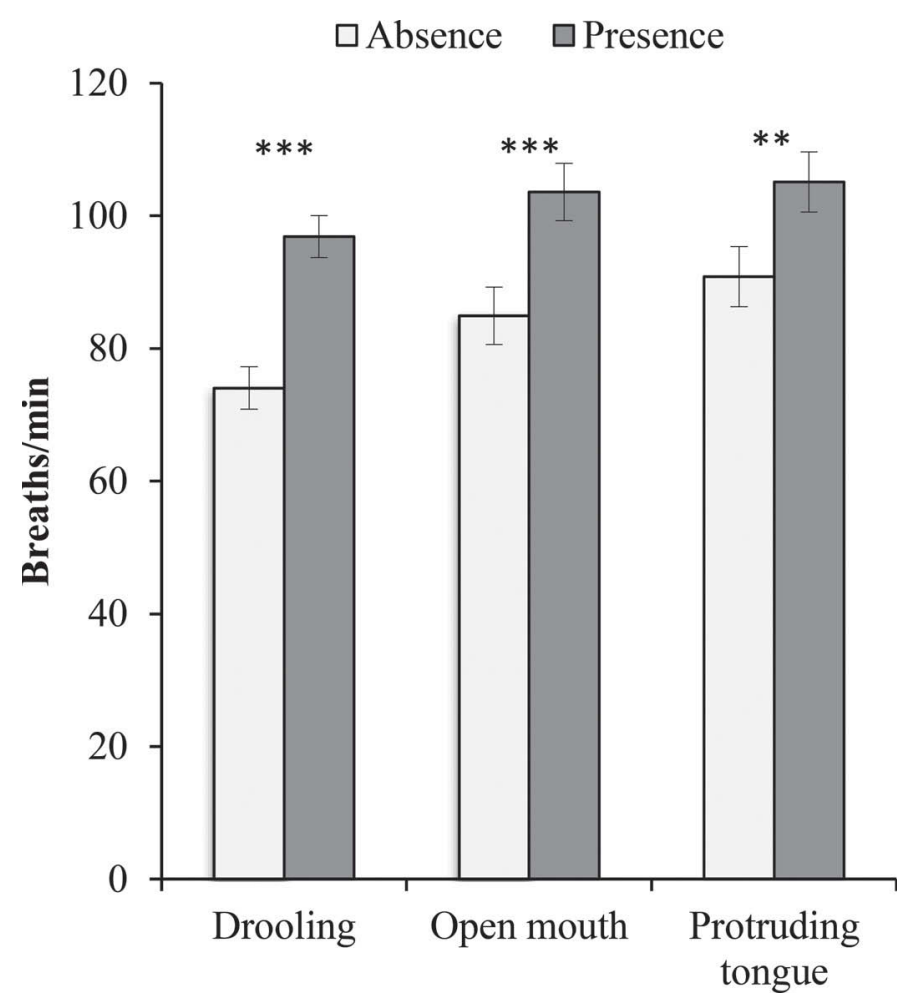

Figure 3. Mean respiration rate in the presence and absence of panting characteristics: drooling $(\mathrm{n}=32)$, open mouth $(\mathrm{n}=21)$, and protruding tongue $(n=15)$. Error bars represent SEM. Differences between presence and absence of each panting characteristic are indicated: ${ }^{* *} P<0.01 ; * * * P<0.001$. 
Table 3. Coefficients of determination $\left(\mathrm{R}^{2}\right)$ for the relationships between data recorded continuously (heat abatement resource use) or every 5 min (physiological parameters), and estimates generated using different sampling intervals ${ }^{1}$

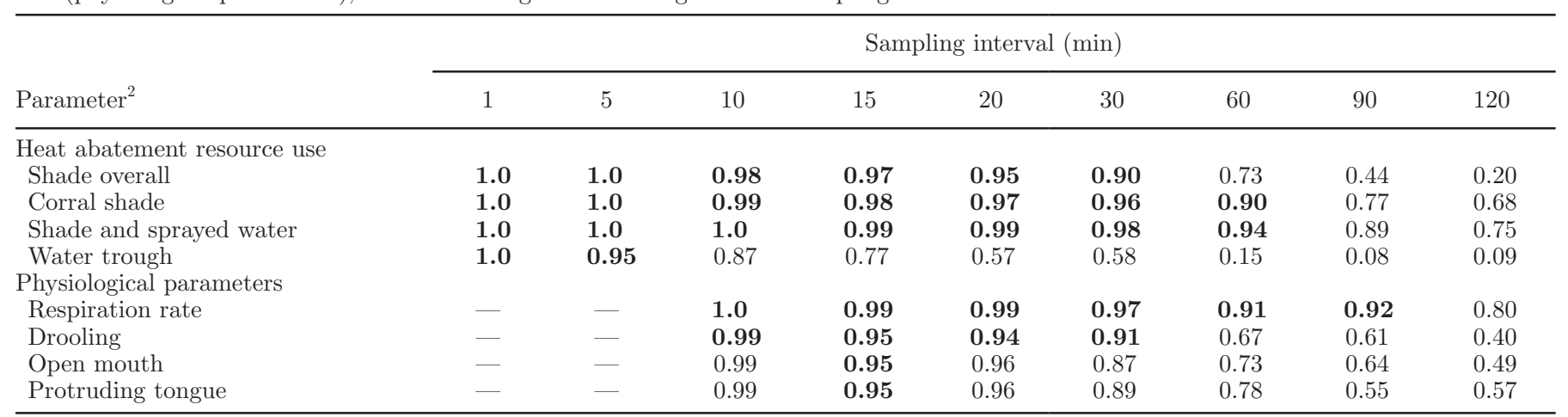

${ }^{1}$ Relationships for which the regression analysis $\mathrm{R}^{2} \geq 0.9$, slope $=1$ and intercept $=0$ are indicated in bold.

${ }^{2}$ Sample size for all measures was $\mathrm{n}=32$, except for shade + sprayed water, where $\mathrm{n}=24$ cows.

truding tongue, cows had a higher respiration rate than when these panting characteristics were absent.

\section{Use of Heat Abatement Resources}

Cows spent $5.9 \mathrm{~h}$ (almost $90 \%$ of the observation period) using any type of shade available in their pens, across 7 visits, on average. When considering the use of the corral shade only, cows spent about $3.2 \mathrm{~h}(50 \%$ of the observation period) using this resource, on average, during 3 visits. Similar amounts of overall shade use have been described for steers housed in feedlots under experimental conditions (81 to $96 \%$ from 1000 to 1900 h; Brown-Brandl et al., 2005). In contrast, the values reported for dairy cows kept on pasture in New Zealand farms were 3 times lower (Schütz et al., 2014), perhaps because these cows did not often have access to feed under shade. Also, lower shade use (7 to $30 \%$ of the observed time) was found for grazing cattle in other experimental studies in New Zealand and Canada, where $\mathrm{T}$ ranged from 20 to $26.5^{\circ} \mathrm{C}$ (Widowski, 2001; Tucker et al., 2008; Schütz et al., 2009). In our study, cows produced more than $30 \mathrm{~kg} / \mathrm{d}$ of milk and average $\mathrm{T}$ during the observation period was $33^{\circ} \mathrm{C}$, which may, in part, explain the greater shade use we observed compared with studies in which cows produced less than 20 $\mathrm{kg} / \mathrm{d}$ and temperatures were cooler (Tucker et al., 2008; Schütz et al., 2009, 2014). The differences in production level and weather can also explain the number of times the cows in the present study visited the corral shade. The number we found (3 visits) was similar to those reported for grazing dry cows given non-solid shade structures in southern Brazil that were observed for a longer period $(12 \mathrm{~h} / \mathrm{d})$ during spring and fall seasons (18 to $23^{\circ} \mathrm{C}$; Coimbra et al., 2012).

To our knowledge, this was the first study reporting bout length for shade use in cattle, which averaged 54 min, regardless of whether cows were using the shade in the corral or feed bunk. Overall, individual bout length ranged from $<1 \mathrm{~min}$ to $4.1 \mathrm{~h}$, and this wide variation may be explained by cattle activity in shaded areas. Longer bouts in the shade may be related to activities such as lying, ruminating, and feeding. The approximate bout duration for corral shade use was similar to the lying bout length (65 min/event) recorded in California free stalls during spring (Ito et al., 2009) and feeding bouts (36 to $47 \mathrm{~min} /$ event) described in other studies (Tolkamp et al., 2000; De Vries et al., 2003b). In contrast, short bouts in the shade may reflect transition periods when cows were moving within the pen.

On average, cows spent $2 \mathrm{~min}$ at the time in areas with no cooling resources, which may indicate reluctance to switch between heat abatement resources or to be directly exposed to the heat during this period of the day. Cows are highly motivated to use shade, especially when the weather is hot (Schütz et al., 2008), and they also prefer feed bunks with spray (Chen et al., 2013). This raises questions about the welfare implications of not providing heat abatement strategies, particularly feed bunks, in drylot systems.

In this study, the total time spent at the feed bunks where shade + sprayed water was provided was $20 \%$ higher than shown by Chen et al. (2013), when average daily $\mathrm{T}$ were $3.4^{\circ} \mathrm{C}$ cooler, but bout length was similar to values described in other studies (42 to 49 min vs. 36 to $47 \mathrm{~min}$; Tolkamp et al., 2000; DeVries et al., 2003b). Our total time results may have been higher than others because we observed cows around feeding and post-milking times, when they were more likely to eat (DeVries et al., 2003a, 2005). In addition, our observations were conducted during the warmest part of the day ( $\mathrm{T}$ was, on average, $5^{\circ} \mathrm{C}$ higher during this period vs. $24 \mathrm{~h}$ periods), when cows were also more likely to use this area to benefit from the sprayed water 
Sampling

interval (min)

10

15

20

30

60 a. Drooling
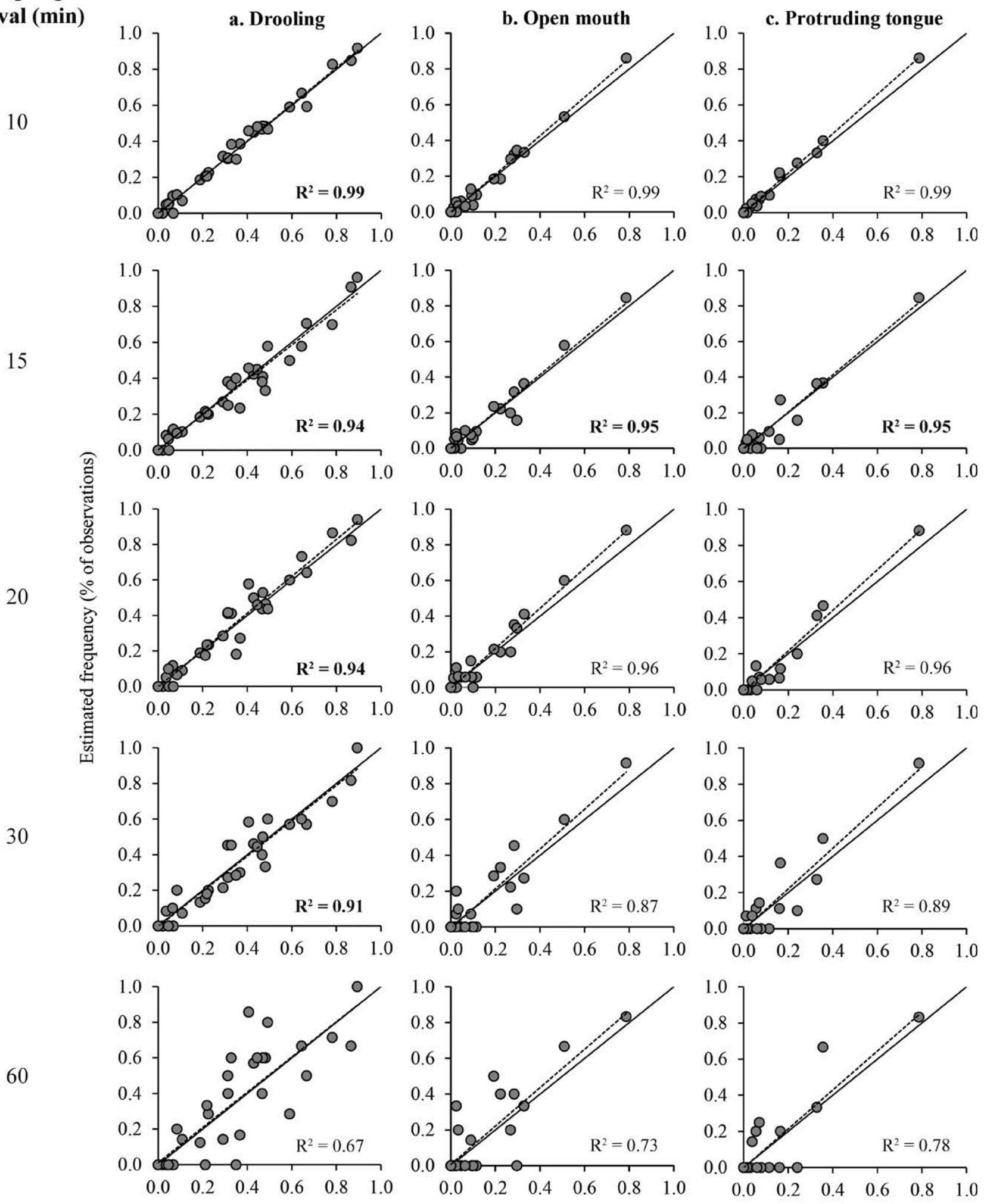

Observed frequency (\% of observations every $5 \mathrm{~min}$ )

Figure 4. Scatterplots of the relationships between observed and estimated frequencies of (a) drooling, (b) open mouth, and (c) protruding tongue for 5 sampling intervals $(10,15,20,30$, and $60 \mathrm{~min}$, top row to bottom row). Dashed lines indicate the line of best fit, and solid lines are provided for reference to a 1:1 relationship. Bold $\mathrm{R}^{2}$ values indicate when relationship has slope $=1$ and intercept $=0$. 
(Chen et al., 2013). The upper range of time spent at the feed bunk (regardless of heat abatement resources provided) was higher than the longest meals reported in another study conducted during the fall in Canada (DeVries et al., 2003b), supporting the idea that cows use this area also for cooling (Chen et al., 2013). The inverse relationship we found between corral shade use and feed bunk use (regardless of heat abatement strategies provided) may indicate that cows trade off when choosing to use one area or the other. A variety of factors may influence cows' decisions about which area to use. Weather (Schütz et al., 2008; Chen et al., 2013), heat abatement strategies provided (Schütz et al., 2009, 2011), flooring (Telezhenko et al., 2007), and feeding times (DeVries et al., 2003a, 2005) likely affect cattle choices regarding which area they prefer to use.

Time spent at the water trough accounted for $3 \%$ of observations across 5 visits, on average, which is at the lower end of the range found in other studies (average T ranged from 23 to $32.6^{\circ} \mathrm{C}$ ) that measured use of this area (range: 1 to $20 \%$ of observations; Widowski, 2001; Schütz et al., 2010; Legrand et al., 2011). The number of visits was similar to drinking behavior recorded over $24 \mathrm{~h}$ periods in mild weather conditions (range: 3.5 to 8 visits, $\mathrm{T}$ averaged from 2 to $16^{\circ} \mathrm{C}$; Andersson, 1987; Jago et al., 2005; Cardot et al., 2008). The duration of each visit was also similar to those found in a study conducted on grazing cows in a smaller radius (approximately $2 \mathrm{~m}$ around the trough; Jago et al., 2005) but longer than drinking bouts (0.7 vs. $2.5 \mathrm{~min} /$ event) described by Dado and Allen (1993). Cows use the area around the water trough in response to heat load (Widowski, 2001; Schütz et al., 2010; Legrand et al., 2011), but the mechanism (e.g., a cooler microclimate or consuming water) remains unclear.

\section{Respiration Rate and Panting}

Respiration rate averaged 80 breaths/min, and was similar to that described during the summer in other open lots in the western United States where cows had access to shade, sprayed water, or a combination of these (Keister et al., 2002; Marcillac-Embertson et al., 2009), but were at least 15 breaths/min higher than grazing cows on New Zealand farms (Schütz et al., 2014). Drooling was the most common panting sign observed (34\% of observations), whereas open mouth and protruding tongue were recorded in $11 \%$ and $8 \%$ of observations, respectively. Panting characteristics were unusual during summer in pastured New Zealand cows (average $\mathrm{T}$ during data collection: $23^{\circ} \mathrm{C}$ ), which exhibited lower respiration rates as well (Schütz et al., 2014). We observed slightly more open mouth than in feedlot cattle housed in unshaded pens during summer in Australia, which showed drooling, open mouth, and protruding tongue frequencies of 34,9 , and $3 \%$, respectively (Gaughan and Mader, 2014).

Respiration rates were similar whether cows exhibited $10 \mathrm{~s}$ intermittent or continuous open mouth or protruding tongue. This result disagreed with Gaughan and Mader (2014), who found that respiration rate was higher for steers breathing with "occasional open mouth" (i.e., intermittent; score 2.5) than "open mouth" (score 3 ). However, attributing the score 2.5 or 3 may depend on the length of observation for that particular feature, which was not specified in their methodology. In addition, they described panting score 2.5 as "fast panting," whereas scores 3 and 3.5 as "rapid panting," a difference that may be difficult to score consistently. Finally, rapid, shallow breath patterns may have a different biological meaning than deep, longer ones, but to date this has not been quantified or investigated, to our knowledge.

Respiration rate was higher when cows exhibited any panting characteristic (drooling, open mouth, and protruding tongue) than when they were not showing any of these signs. Similarly, respiration rates of beef steers averaged at least 96 breaths/min when they showed panting characteristics, and were relatively lower $(\leq 53$ breaths/min) in their absence (Gaughan and Mader, 2014). In other studies where these panting characteristics were rarely recorded, respiration rates were relatively lower (mean respiration rate: 65 and 50 breaths/ min, respectively; Schütz et al., 2010; Legrand et al., 2011) than in this work and used either dry (average $\mathrm{T}$ during data collection: $32.6^{\circ} \mathrm{C}$; Legrand et al., 2011) or low-producing cows (average $\mathrm{T}$ during data collection: $23^{\circ} \mathrm{C}$; Schütz et al., 2011). Further study is needed to understand the biological relevance of each panting characteristic in terms of heat loss. For example, in dogs, exposing the tongue seems to encourage heat loss through convection (Krönert and Pleschka, 1976; Pleschka et al., 1979), but little is known about this mechanism in cattle. Furthermore, it is unclear whether drooling is directly associated with cooling, or is an artifact of cows opening their mouths; we found $80 \%$ of the open mouth and protruding tongue events were accompanied by drooling.

\section{Sampling Intervals}

This is the first study to validate sampling intervals to assess the use of heat abatement resources by dairy cattle, their respiration rate, and panting characteristics. Across studies, the use of heat abatement resources has been measured using sampling intervals that vary from 10 (Coimbra et al., 2012; Parola et al., 2012) to 120 (Sullivan et al., 2011) and 240 min (Mader et al., 
2007) for shade and sprayed water. In this study, we found that use of resources such as corral shade and shade + sprayed water could be measured accurately using intervals up to $60 \mathrm{~min}$, which is similar to the duration of the visits in these areas (54 and $49 \mathrm{~min}$, respectively). In contrast, for resources where cows spent little time, such as the water trough, the use of sampling intervals $>5$ min did not accurately reflect continuous observations. This was likely because cows did not visit this resource very often ( 5 visits on average) and the average visit duration (2.5 $\mathrm{min})$ was at the lower end of the sampling intervals we tested, increasing the probability of missing an entire bout.

Respiration rate was accurately estimated using sampling intervals $\leq 90 \mathrm{~min}$. Relative to cattle use of heat abatement resources, longer sampling intervals accurately reflected respiration rate. Respiration rate can be affected by the weather (Brown-Brandl et al., 2005; Schütz et al., 2008; Parola et al., 2012), the quantity and type of heat abatement resources provided (Kendall et al., 2007; Schütz et al., 2010; Chen et al., 2015), and cattle preference to use different areas in the pen. All of these features are likely to be relatively stable over $90 \mathrm{~min}$.

Accurate estimates of drooling were obtained when using sampling intervals $\leq 30 \mathrm{~min}$. One study sampled panting within this range (Schütz et al., 2014), but others measured every hour (Legrand et al., 2011) or twice a day (Brown-Brandl et al., 2006). We were unable to determine accurate sampling intervals for open mouth and protruding tongue, perhaps because we observed these panting characteristics infrequently. Another aspect that may affect the choice of sampling intervals is the cyclicity of the response. For example, if cows alternate open mouth and protruding tongue with normal breathing in a regular pace, it could be possible that even short intervals (i.e., $<5 \mathrm{~min}$ ) would not accurately capture such characteristics. Further work is required to evaluate whether panting follows a biological rhythm.

\section{CONCLUSIONS}

This is the first study to describe cattle use of heat abatement resources on commercial drylot dairies and to validate the use of sampling intervals to measure responses to heat load in cattle. Under hot and dry environmental conditions, cows kept in this housing system had higher respiration rate when panting (i.e., drooling, open mouth, or protruding tongue) compared with when these panting signs were not observed. Cows used heat abatement resources extensively, avoiding areas with no cooling throughout the warmest part of the day. In general, 30 min intervals were most efficient for measuring heat load responses in drylot cattle.

\section{ACKNOWLEDGMENTS}

We are grateful to Priscila Cruz (supported by the Science Without Borders Program, Brasilia, Brazil, and located at the University of California-Davis during the study) who helped with data collection and all the dairy farmers and managers who participated in this study. Many thanks also to Erin Mintline, Jennifer Chen, Melissa Jordan, and Peter Robinson, all affiliated with the University of California-Davis at the time of the study. We gratefully acknowledge the financial support of CAPES Foundation (Brasilia, Brazil; process BEX 0764/12-4, awarded to G. Tresoldi), Jastro Shields Award (Davis, CA), USDA multi-state research project W2173 (Washington, DC), and the infrastructure support of the Department of Animal Science and the College of Agricultural and Environmental Sciences of the University of California-Davis.

\section{REFERENCES}

Andersson, M. 1987. Effects of number and location of water bowls and social rank on drinking behaviour and performance of loosehoused dairy cows. Appl. Anim. Behav. Sci. 17:19-31.

Brown-Brandl, T. M., R. A. Eigenberg, G. L. Hahn, J. A. Nienaber, T. L. Mader, D. E. Spiers, and A. M. Parkhurst. 2005. Analyses of thermoregulatory responses of feeder cattle exposed to simulated heat waves. Int. J. Biometeorol. 49:285-296.

Brown-Brandl, T. M., R. A. Eigenberg, and J. A. Nienaber. 2006. Heat stress risk factors of feedlot heifers. Livest. Sci. 105:57-68.

Cardot, V., Y. Le Roux, and S. Jurjanz. 2008. Drinking behavior of lactating dairy cows and prediction of their water intake. J. Dairy Sci. 91:2257-2264.

Chen, J. M., K. E. Schütz, and C. B. Tucker. 2013. Dairy cows use and prefer feed bunks fitted with sprinklers. J. Dairy Sci. 96:5035-5045.

Chen, J. M., K. E. Schütz, and C. B. Tucker. 2015. Cooling cows efficiently with sprinklers: Physiological responses to water spray. J. Dairy Sci. 98:6925-6938.

Coimbra, P. A. D., L. C. P. Machado Filho, and M. J. Hötzel. 2012. Effects of social dominance, water trough location and shade availability on drinking behaviour of cows on pasture. Appl. Anim. Behav. Sci. 139:175-182.

Dado, R. G., and M. S. Allen. 1993. Continuous computer acquisition of feed and water intakes, chewing, reticular motility, and ruminal pH of cattle. J. Dairy Sci. 76:1589-1600.

DeVries, T. J., M. A. G. von Keyserlingk, and K. A. Beauchemin. 2003a. Diurnal feeding pattern of lactating dairy cows. J. Dairy Sci. 86:4079-4082.

DeVries, T. J., M. A. G. von Keyserlingk, and K. A. Beauchemin. 2005. Frequency of feed delivery affects the behavior of lactating dairy cows. J. Dairy Sci. 88:3553-3562.

DeVries, T. J., M. A. G. von Keyserlingk, D. M. Weary, and K. A. Beauchemin. 2003b. Measuring the feeding behavior of lactating dairy cows in early to peak lactation. J. Dairy Sci. 86:3354-3361.

Gaughan, J. B., and T. L. Mader. 2014. Body temperature and respiratory dynamics in un-shaded beef cattle. Int. J. Biometeorol. 58:1443-1450.

Gaughan, J. B., T. L. Mader, S. M. Holt, and A. Lisle. 2008. A new heat load index for feedlot cattle. J. Anim. Sci. 86:226-234.

Ito, K., D. M. Weary, and M. A. G. von Keyserlingk. 2009. Lying behavior: assessing within- and between-herd variation in free-stallhoused dairy cows. J. Dairy Sci. 92:4412-4420.

Jago, J. G., J. R. Roche, E. S. Kolver, and M. W. Woolford. 2005. The drinking behaviour of dairy cows in late lactation. Pages 209-214 
in Proc. N. Z. Soc. Anim. Prod. New Zealand Soc. Anim. Prod., Christchurch, New Zealand.

Keister, Z. O., K. D. Moss, H. M. Zhang, T. Teegerstrom, R. A. Edling, R. J. Collier, and R. L. Ax. 2002. Physiological responses in thermal stressed Jersey cows subjected to different management strategies. J. Dairy Sci. 85:3217-3224.

Kelly, C. F., and T. E. Bond. 1971. Bioclimatic factors and their measurement. Page 77 in A Guide to Environmental Research on Animals. National Academies Press, Washington, DC.

Kendall, P. E., G. A. Verkerk, J. R. Webster, and C. B. Tucker. 2007. Sprinklers and shade cool cows and reduce insect-avoidance behavior in pasture-based dairy systems. J. Dairy Sci. 90:3671-3680.

Krönert, H., and K. Pleschka. 1976. Lingual blood flow and its hypothalamic control in the dog during panting. Pflugers Arch. $367: 25-31$.

Ledgerwood, D. N., C. Winckler, and C. B. Tucker. 2010. Evaluation of data loggers, sampling intervals, and editing techniques for measuring the lying behavior of dairy cattle. J. Dairy Sci. 93:5129-5139.

Legrand, A., K. E. Schütz, and C. B. Tucker. 2011. Using water to cool cattle: Behavioral and physiological changes associated with voluntary use of cow showers. J. Dairy Sci. 94:3376-3386.

Mader, T. L., M. S. Davis, and T. M. Brown-Brandl. 2006. Environmental factors influencing heat stress in feedlot cattle. J. Anim. Sci. 84:712-719.

Mader, T. L., M. S. Davis, and J. B. Gaughan. 2007. Effect of sprinkling on feedlot microclimate and cattle behavior. Int. J. Biometeorol. 51:541-551.

Marcillac-Embertson, N. M., P. H. Robinson, J. G. Fadel, and F. M. Mitloehner. 2009. Effects of shade and sprinklers on performance, behavior, physiology, and the environment of heifers. J. Dairy Sci. 92:506-517.

Martin, P., and P. Bateson. 2007. Recording methods. Pages 48-61 in Measuring Behavior: An Introductory Guide. 3rd ed. Cambridge Univ. Press, Cambridge, UK.

Mitlöhner, F. M., J. L. Morrow-Tesch, S. C. Wilson, J. W. Dailey, and J. M. McGlone. 2001. Behavioral sampling techniques for feedlot cattle. J. Anim. Sci. 79:1189-1193.

Parola, F., E. Hillmann, K. E. Schütz, and C. B. Tucker. 2012. Preferences for overhead sprinklers by naïve beef steers: Test of two nozzle types. Appl. Anim. Behav. Sci. 137:13-22.

Pleschka, K., P. Kühn, and M. Nagai. 1979. Differential vasomotor adjustments in the evaporative tissues of the tongue and nose in the dog under heat load. Pflugers Arch. 382:255-262.

SAS Institute. 2009. SAS/STAT 9.2 User's Guide. Vol. 2. SAS Institute Inc., Cary, NC.
Schütz, K. E., N. R. Cox, and L. R. Matthews. 2008. How important is shade to dairy cattle? Choice between shade or lying following different levels of lying deprivation. Appl. Anim. Behav. Sci. 114:307-318.

Schütz, K. E., N. R. Cox, and C. B. Tucker. 2014. A field study of the behavioral and physiological effects of varying amounts of shade for lactating cows at pasture. J. Dairy Sci. 97:3599-3605.

Schütz, K. E., A. R. Rogers, N. R. Cox, and C. B. Tucker. 2009. Dairy cows prefer shade that offers greater protection against solar radiation in summer: Shade use, behaviour, and body temperature. Appl. Anim. Behav. Sci. 116:28-34.

Schütz, K. E., A. R. Rogers, N. R. Cox, J. R. Webster, and C. B. Tucker. 2011. Dairy cattle prefer shade over sprinklers: effects on behavior and physiology. J. Dairy Sci. 94:273-283.

Schütz, K. E., A. R. Rogers, Y. A. Poulouin, N. R. Cox, and C. B. Tucker. 2010. The amount of shade influences the behavior and physiology of dairy cattle. J. Dairy Sci. 93:125-133.

St-Pierre, N. R., B. Cobanov, and G. Schnitkey. 2003. Economic losses from heat stress by US livestock industries. J. Dairy Sci. 86(ESuppl.):E52-E77.

Stokes, S., and M. Gamroth. 1999. Freestall Dairy Facilities in Central Texas. Vol. L-5311. Texas A\&M System, AgriLife Extension, College Station, TX.

Sullivan, M. L., A. J. Cawdell-Smith, T. L. Mader, and J. B. Gaughan. 2011. Effect of shade area on performance and welfare of short-fed feedlot cattle. J. Anim. Sci. 89:2911-2925.

Telezhenko, E., L. Lidfors, and C. Bergsten. 2007. Dairy cow preferences for soft or hard flooring when standing or walking. J. Dairy Sci. 90:3716-3724.

Tolkamp, B. J., D. P. N. Schweitzer, and I. Kyriazakis. 2000. The biologically relevant unit for the analysis of short-term feeding behavior of dairy cows. J. Dairy Sci. 83:2057-2068.

Tucker, C. B., A. R. Rogers, and K. E. Schütz. 2008. Effect of solar radiation on dairy cattle behaviour, use of shade and body temperature in a pasture-based system. Appl. Anim. Behav. Sci 109:141-154.

USDA. 2010. Facility Characteristics and Cow Comfort on U.S. Dairy Operations, 2007. USDA-APHIS-VS, CEAH, Fort Collins, CO.

von Keyserlingk, M. A. G., N. P. Martin, C. J. Sniffen, J. P. Harner III, A. D. Wright, and S. I. Smith. 2013. Invited review: Sustainability of the US dairy industry. J. Dairy Sci. 96:5405-5425.

Widowski, T. 2001. Shade-seeking behavior of rotationally-grazed cows and calves in a moderate climate. Pages 632-639 in Livest. Environ. VI: 6th Int. Symp., ASAE, Louisville, KY. 